\title{
Establishment of an analytical method for butaphosphan (BTP), a stress-attenuating agent, and its application in the preliminary pharmacokinetic evaluation of residues in olive flounder Paralichthys olivaceus
}

\author{
Ji-Hoon Lee', Jun Sung Bae ${ }^{2}$, Chae Won Lee ${ }^{2}$, Chan Yeong Yang ${ }^{2}$, Ji-Sung Choi ${ }^{2}$, Sang-Hoon Choi²,
} Yue-Jai Kang ${ }^{3}$ and Kwan Ha Park ${ }^{2^{*}}$

\begin{abstract}
Background: Butaphosphan (BTP) has recently been introduced into the Korean aquaculture sector as a stressattenuating agent. In this study, a sensitive chemical analytical method was established for the detection of BTP in the olive flounder (Paralichthys olivaceus) tissues.

Methods: Utilizing a method employing liquid chromatography coupled with tandem mass spectrometry (LC-MS/ MS), detection sensitivity, specificity, and precision were satisfactorily established. Temporal changes in the BTP plasma and muscle concentrations were assessed after a single intramuscular injection of BTP (50 and $150 \mathrm{mg} / \mathrm{kg}$ ) to the olive flounder maintained at $13^{\circ} \mathrm{C}$ or $22^{\circ} \mathrm{C}$.

Results: High BTP plasma levels were achieved immediately after the injection, and the drug was rapidly eliminated. Additionally, plasma BTP levels were markedly dependent on the elimination rate, which, in turn, seemed dependent on the water temperature, with the drug elimination half-life and mean residence time significantly shorter at $22^{\circ} \mathrm{C}$ than $13^{\circ} \mathrm{C}$. Overall, muscle BTP levels were markedly lower than the plasma levels. Notably, muscle levels were not influenced by water temperatures. Muscle BTP concentrations were used to estimate the necessary withdrawal period for drugs used in food fish, with BTP levels maintained far below the possible hazardous limit.
\end{abstract}

Conclusions: In conclusion, the established LC-MS/MS method can be used for BTP residue detection with high sensitivity and reproducibility.

Keywords: Butaphosphan (BTP), Olive flounder P. olivaceus, Plasma and muscle concentrations, Residue pharmacokinetics

\footnotetext{
* Correspondence: khpark@kunsan.ac.kr

${ }^{2}$ Department of Aquatic Life Medicine, College of Ocean Science \&

Technology, Kunsan National University, 558 Daehak-ro, Gunsan City,

Jeonbuk 54150, Korea

Full list of author information is available at the end of the article
}

(c) The Author(s). 2020 Open Access This article is licensed under a Creative Commons Attribution 4.0 International License, which permits use, sharing, adaptation, distribution and reproduction in any medium or format, as long as you give appropriate credit to the original author(s) and the source, provide a link to the Creative Commons licence, and indicate if changes were made. The images or other third party material in this article are included in the article's Creative Commons licence, unless indicated otherwise in a credit line to the material. If material is not included in the article's Creative Commons licence and your intended use is not permitted by statutory regulation or exceeds the permitted use, you will need to obtain permission directly from the copyright holder. To view a copy of this licence, visit http://creativecommons.org/licenses/by/4.0/ 


\section{Introduction}

Butaphosphan (1-butylamino-1-methylethyl-phosphonic acid, BTP, Fig. 1) has been used in several domestic animals, usually in combination with vitamin $B_{12}$, to attenuate the symptoms stress occurring during various situations. After calving in dairy cows, BTP is believed to improve metabolic ketosis and milk production during the postpartum period (Pereira et al. 2013a; Rolling et al. 2010; Tabeleão et al. 2017). Additionally, the drug is helpful in cows recovering from surgical procedures (Fürll et al. 2006; Fürll et al. 2010). In sheep stressed due to drug treatments, BTP improved appetite and metabolic adjustments (Pereira et al. 2013b). In piglets, an assessment of cortisol levels and behavioral changes has indicated reduced social stress induced by co-housing with unfamiliar individuals (Van der Staay et al. 2007). In dogs, BTP prevents abnormalities in hepatic function and digestive enzyme activity caused by an antiinflammatory steroid (Deniz et al. 2009). Furthermore, BTP pretreatment reportedly improved endurance in rodents (Hasi et al. 2004, 2005a, 2005b).

Although BTP has long been widely used in various livestock animals against stress-related symptoms, its pharmacological effects in fish species have remained unclear until recently. We recently recognized the usefulness of BTP as a stress-attenuating agent against conditions like hypothermia, hypoxia, or antibiotic drug injections in olive flounder: cortisol levels, reduced appetite, and immune parameters were partially prevented after injection of BTP (Seo et al. 2019). Additionally, BTP attenuates stress-induced immune-suppression and tissue damage (Mechesso et al. 2019) following over-crowding of the olive flounder. In fishes, some earlier preliminary reports have suggested possible beneficial effects, although their work may require further confirmatory studies. For example, it has been reported that maternally injected BTP improved spawning rates and relative fecundity in Nile tilapia (Alkobaby 2008). Van de Vis et al. (2004) examined whether BTP can alleviate hypoxia-stress symptoms in sole fish but failed to definitively conclude its effectiveness.
Based on recent reports, BTP is now prescribed in farms for relieving stress symptoms in Korean olive flounder aquaculture (National Institute of Fisheries Sciences 2018).

Despite actual application in veterinarian fields, the mechanism of action of BTP remains unclear. It has been suggested that stress-attenuating effects may be associated with the accelerated production of adenosine5'-triphosphate (ATP) after BTP administration to mice (Hasi et al. 2004) or fish (Seo et al. 2019).

Information concerning drug's pharmacokinetic behavior is essential to understand the duration of action and chemical clearance time, particularly when the safety of a drug is unknown. To perform a pharmacokinetic assessment, the establishment of an analytical method is a prerequisite. Analytical procedures for BTP have been developed for piglets (Sun et al. 2016) and horses (Du 2004); however, no attempt has been made to develop a procedure suitable in fish tissues.

This study was performed to delineate the pharmacokinetic profiles of BTP in the olive flounder, a major target for the use of BTP. The analytical method utilized for the olive flounder was established using liquid chromatography coupled with mass spectrometry (LC-MS/ MS), which is highly powerful for the analysis of many organic chemical drugs.

\section{Materials and methods}

Fish husbandry

Olive flounder $P$. olivaceus, weighing $105 \pm 5 \mathrm{~g}$, were obtained from a culture farm located in Taean County, Chungnam Province, Korea, and maintained in recirculating seawater culture tanks of L3.0 $\mathrm{m} \times \mathrm{W} 1.0 \mathrm{~m} \times \mathrm{H} 1.2 \mathrm{~m}$, at a density of about 20 fish/tank. The water level was maintained at $0.8 \mathrm{~m}$, dissolved oxygen $6.0 \mathrm{ppm}$, and a temperature of $22 \pm 3{ }^{\circ} \mathrm{C}$. In some studies, the temperature was set at $13 \pm 3{ }^{\circ} \mathrm{C}$ to examine the temperature effect. A commercial flounder pellet feed (CJ Feed Inc., Gunsan, Jeonbuk, Korea) was supplied at a rate of approximately $3 \%$, twice daily at 9:00 AM and 6:00 PM. Experimental

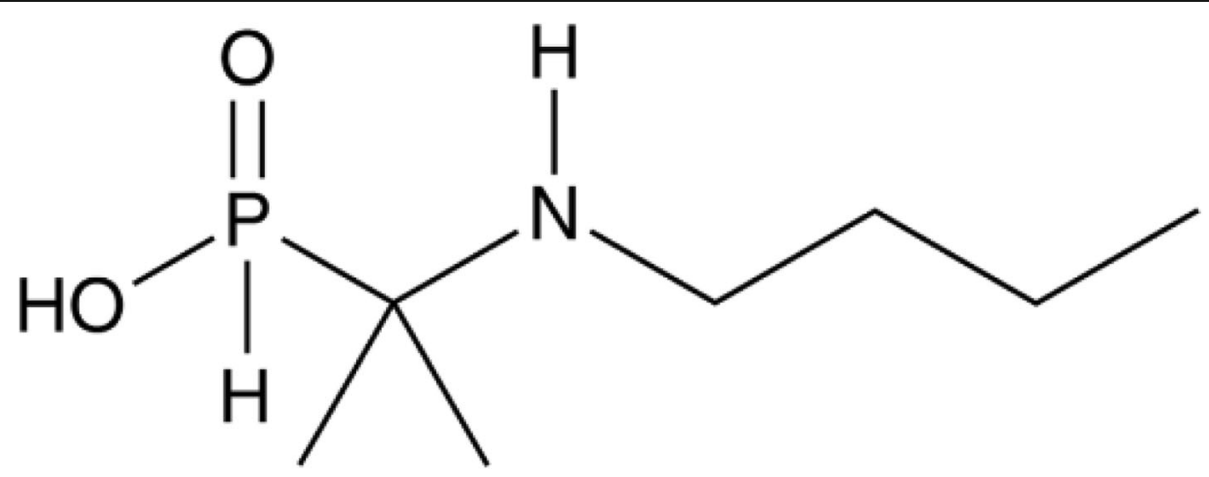

Fig. 1 Chemical structure of 1-(butylamino)-1-methylethyl]-phosphonic acid in BTP (active component) 
protocols were approved by the Animal Care and Use Committee of the Kunsan National University, Korea (Approval number, AE 2016-04).

\section{Test drug and analytical reagents}

The test drug used was a commercially available combination product of [1-(butylamino)-1-methylethyl]-phosphonous acid $100 \mathrm{mg} / \mathrm{ml}$ and cyanocobalamin (vitamin $\mathrm{B}_{12}$ ) $50 \mu \mathrm{g} / \mathrm{ml}$ as an injectable aqueous solution (TITAN $^{\circledR}$, Korea BNP, Yesan, Chungnam, Korea). In this study, this complex test drug was referred to as BTP (Fig. 1) and was diluted in $0.85 \%$ saline before the intramuscular injection at $0.5 \mathrm{ml} / \mathrm{kg}$ body weight. Most analytical reagents were obtained from Sigma (St. Louis, MO, USA) unless otherwise specified.

\section{BTP analysis using LC-MS/MS technique}

BTP analysis was performed using high-performance liquid chromatography coupled with tandem mass spectrometry (LC-MS/MS). The analytical system was composed of Agilent-6420 model triple quadrupole detectors with an ionization spray as the ionization source (Agilent Technologies, Santa Clara, CA, USA). LC column used was Xbridge $C_{18}(2.1 \times 150 \mathrm{~mm}, 3.5 \mu \mathrm{m}$, Waters $)$, and the mobile phase was composed of two solutions, pure water (A) and 100\% methanol (B), both containing $0.1 \%$ formic acid. Elution was performed by a linear gradient change at $0.2 \mathrm{~mL} / \mathrm{min}$ : flow through the LC column was started with $90 \%$ solution A for $1 \mathrm{~min}, 20 \%$ A over a 10 -min period, and then a brief switch to $90 \% \mathrm{~A}$ at the end of the run to flush for the next $10 \mathrm{~min}$. This mobile phase properly eluted the target molecule BTP under positive ESI conditions. The column temperature was set at $35^{\circ} \mathrm{C}$ and $10 \mu \mathrm{L}$ injection volume was used. Table 1 summarizes the mass detector conditions for all ions involved. In addition, the capillary temperature was set at $450{ }^{\circ} \mathrm{C}$ and nitrogen $\left(\mathrm{N}_{2}\right)$ was used as the collision gas. Calibration curves were obtained with BTP dissolved in $0.1 \%$ formic acid at a wide range of concentrations.

\section{Validation of LC-MS/MS analytical method}

Validation of the BTP analytical technique was performed for muscle tissues as the lowest residue levels have usually been observed in the muscle after most drug administrations. The linearity test was performed with working solutions ranging from 1 to $500 \mu \mathrm{g} / \mathrm{kg}$. Detection and quantification limits were obtained from signal to noise ratios of 3:1 and 10:1, respectively. The degree of precision was estimated by the intra- and inter-day repeatability with 2.5 and $25 \mu \mathrm{g} / \mathrm{kg}$ BTP. The recovery was estimated by comparing signal magnitudes between standard solutions and spiked samples.

\section{BTP Injection to fish for pharmacokinetic and muscle residue studies}

BTP was injected into the dorsal muscle of the olive flounder at 50 and $150 \mathrm{mg} / \mathrm{kg}$ doses. Immediately before injection, BTP was diluted to the requisite concentrations in saline. Fish samples were obtained at 0, 0.5, 1, 5, 12, 24, 48, 168 (7 days), and $335 \mathrm{~h}$ (14 days) after BTP injection. Blood was withdrawn under MS-222 anesthesia (20 mg/l) using heparinized syringes through the caudal vessels. Next, the fish were sacrificed for muscle dissection. In each group, 10 fish were allocated for each time point. All 10 fish were used for muscle analysis, whereas five random samples were utilized for plasma level analysis. Muscle levels were examined primarily to ascertain food safety.

\section{Sample treatment for BTP extraction}

BTP extraction from plasma and muscle tissues was performed as described by Du et al. (2004) with some modifications. Plasma was obtained by blood centrifugation for $30 \mathrm{~min}$ at $3000 \times \mathrm{g}$ under refrigeration. The plasma $(500 \mu \mathrm{l})$ was mixed with an equal volume of methanol and centrifuged at $4000 \times g$ to obtain the supernatant. The supernatant was mixed with phosphate-buffered saline (100 mM, pH 3.5), and loaded onto $\mathrm{C}_{18}$ solid-phase extraction cartridges (SepPak ${ }^{\bullet}$, Waters, Milford, MA, USA), pre-activated with $2 \mathrm{ml}$ methanol and distilled water. The cartridges were cleaned with $2 \mathrm{ml}$ distilled water, and then BTP was eluted with $2 \mathrm{ml}$ methanol. BTP in the methanol eluate was concentrated to dryness under nitrogen at $47^{\circ} \mathrm{C}$. Residues were reconstituted in $1 \mathrm{ml}$ of $0.1 \%$ formic acid and filtered using $0.2 \mu \mathrm{m}$ syringe nylon filters (SigmaAldrich). For muscle BTP analysis, tissues (2 g) were homogenized in $5 \mathrm{ml}$ methanol and centrifuged for $10 \mathrm{~min}$ at $3000 \times g$. The supernatant was pooled and the pellet was resuspended in methanol to repeat the centrifugation process. The pooled supernatant was concentrated at $35^{\circ} \mathrm{C}$ to dryness. Residues were reconstituted in $1.5 \mathrm{ml}$ phosphate-buffered saline and samples were processed through identical clean-up steps as described for plasma samples.

Table 1 Multiple reaction monitoring (MRM) mode for detection of butaphosphan (BTP)

\begin{tabular}{llllll}
\hline Analyte & Retention time $(\mathrm{min})$ & Molecular weight & Precursorion $(\mathrm{m} / \mathrm{z})$ & Production $(\mathrm{m} / \mathrm{z})$ & Collision energy $(\mathrm{eV})$ \\
\hline Butaphosphan & 4.07 & 179.20 & 180.0 & 114.1 & 4 \\
Butaphophan & 4.07 & 179.20 & 180.0 & 72.2 & 28 \\
Butaphophan & 4.07 & 179.20 & 180.0 & 58.1 & 31 \\
\hline
\end{tabular}




\section{Data analyses}

Data are expressed as mean \pm SD when appropriate for multiple determinations. Pharmacokinetic parameters were analyzed using the PKSolver program developed by Zhang et al. (2010). As the plasma BTP concentration did not fit any model, a non-compartmental model was applied to analyze pharmacokinetic parameters (Zhang et al. 2010). Additionally, this model examined whether a withdrawal period for the olive flounder can be determined using an analytical program (Hekman 1996) based on the observed muscle BTP levels. For this estimation, acceptable daily intake data (European Medicines Agency 2013), estimated daily fish product consumption by Koreans (63 g/day, Korea Rural Economic Institute, 2017), and exposure estimation methods (Korea Ministry of Food and Drug Administration 2017) were applied.

\section{Results}

\section{Analytical method quality validation}

Figure 2 shows multiple residue monitoring (MRM) chromatograms developed for olive flounder tissue analysis and a standard curve of BTP spiked muscles. In the muscles, spiked BTP was clearly discernable from interfering substance signals and a wide range of BTP concentrations maintained linearity in signal magnitudes $\left(r^{2}>0.9995\right)$.

A summary of the analytical precision performed with two different BTP concentrations after spiking muscle tissues is shown in Table 2. The limit of quantification was $2.5 \mu \mathrm{g} / \mathrm{kg}$, with the recovery rates ranging around $100 \%$ in both the intra- and inter-day reproducibility tests.

\section{Residue pharmacokinetic characteristics}

Figure 3 shows changes in plasma BTP concentrations following the intramuscular administration of BTP at 50 and $150 \mathrm{mg} / \mathrm{kg}$. In general, the $150 \mathrm{mg} / \mathrm{kg}$ BTP dose resulted in higher peak BTP concentrations than the $50 \mathrm{mg} / \mathrm{kg}$ dose. Interestingly, however, once peak concentrations were achieved following each dose, lower levels were observed in fish maintained at $22^{\circ} \mathrm{C}$ during the elimination phase than those at $13^{\circ} \mathrm{C}$. Another interesting characteristic was the biphasic peak concentration pattern, in which the initial lower level peaks were accompanied by secondary higher peaks. The pharmacokinetic patterns were analyzed to obtain kinetic parameters as shown in Table 3. Peak plasma concentrations $\left(C_{\max }\right)$ were roughly dosedependent when compared between the two doses. However, the elimination half-lives were shorter at $22^{\circ} \mathrm{C}$ than at $13^{\circ} \mathrm{C}$. This faster disappearance at higher temperatures was reflected as shorter elimination half-lives $\left(t_{1 / 2 \mathrm{E}}\right)$, shorter mean residence time (MRT), and smaller areaunder the curve (ACU) of BTP at $22^{\circ} \mathrm{C}$ compared to their matching doses at $13^{\circ} \mathrm{C}$.

The pattern of muscle BTP concentrations is shown in Fig. 4. Muscle concentrations were also dose-dependent at peak concentrations between 50 and $150 \mathrm{mg} / \mathrm{kg}$. However, the peak levels were markedly lower in comparison with the plasma concentration after the equivalent doses and water temperatures. However, patterns between the two temperatures, no differences in the elimination phase were observed. Overall, no marked difference in concentrations was noted between the two temperatures within the same injection dose (Table 4).

In all sets of experiments, BTP was not detected in plasma or right muscle after test drug injections, excluding the possibility of recent BTP administration.

\section{Estimation of BTP residue standard and withdrawal time}

Figure 5 presents the edible tissue (muscle) concentration over time after BTP injection and maximally acceptable tissue concentrations for food uses (European Medicines Agency 2013). As the acceptable daily intake (ADI) of BTP is $0.6 \mathrm{mg} / \mathrm{kg}$, a person can tolerate up to $36 \mathrm{mg} /$ day (60 kg body weight, $60 \times 0.6=36$ ). In the fish muscle, this can result in as much as $571.4 \mathrm{mg} / \mathrm{kg}$ BTP theoretically acceptable for safe consumption (daily consumption of $63 \mathrm{~g}$ fishery products, $1000 \div 63 \times 36=571.4)$. Evidently, the muscle levels of BTP were far below the top broken lines $\left(571.4 \mathrm{mg} / \mathrm{kg}\right.$ ) at any time point, in both $13{ }^{\circ} \mathrm{C}$ and $22^{\circ} \mathrm{C}$. This large separation from the limit level and actual muscle concentrations, even at peak levels, rendered withdrawal time setting unnecessary.

\section{Discussion}

This study was designed to develop a sensitive analytical method for the pharmacokinetic analysis of butaphosphan (BTP). Although BTP has widely been prescribed to attenuate stress symptoms in both domestic and aquaculture sectors (Deniz et al. 2009; Fürll et al. 2006; Fürll et al. 2010; Mechesso et al. 2019; Pereira et al. 2013a, 2013b; Rolling et al. 2010; Seo et al. 2019; Tabeleão et al. 2017; Van der Staay et al. 2007), analytical procedures have not well been described. In addition, understanding the pharmacokinetic characteristics of a drug is crucial to estimate the onset, duration, and termination of biological activities (Benez 1984). Furthermore, pharmacokinetic information is essential to assess the consumer safety of a drug if its residues are possibly hazardous to humans.

The analytical method for BTP determination using a singular LC-MS was developed by Du (2004), reporting the quantification limit of $0.01 \mathrm{mg} / \mathrm{kg}$ in piglet tissues. More recently, Sun et al. (2016) used an advanced LC-MS/MS method, a tandem MS system, to analyze BTP in piglet plasma samples with a quantifiable level of $0.05 \mathrm{mg} / \mathrm{l}$. In studies by both Du et al. (2004) and Sun et al. (2016), recovery from the above animal tissues was excellent and nearly $100 \%$. In the present study, a level as low as 0.0025 $\mathrm{mg} / \mathrm{kg}$ was quantifiable, indicating over 4 times the sensitivity than methods reported in previous studies ( Du 2004; 


\section{A. Blank}



\section{B. Standard BTP 0.5 pg}

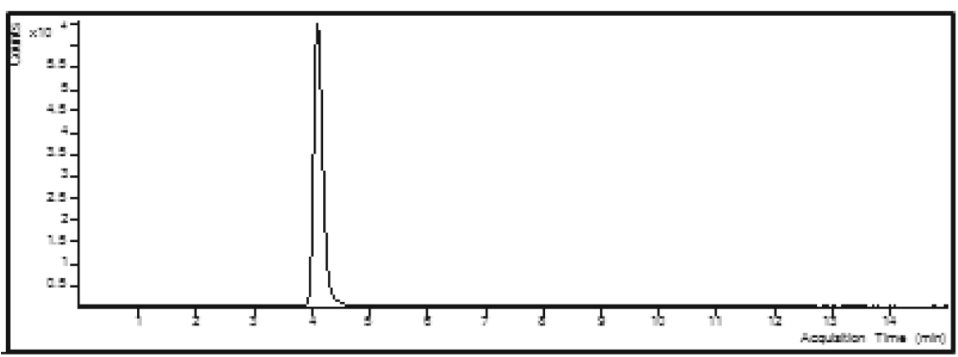

\section{Extracted BTP after spiking to olive flounder muscle, $0.025 \mathrm{pg}$}

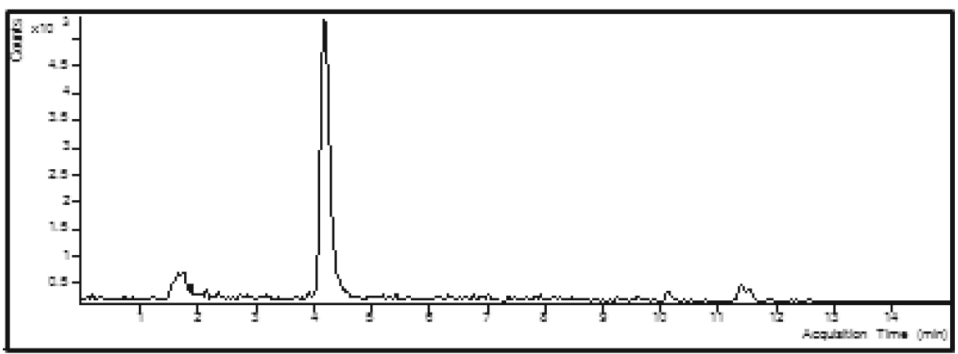

\section{Standard curve of BTP}



Fig. 2 Representative LC-MS/MS chromatograms and standard curve of BTP. a Blank. b Standard BTP 0.5 pg. c Extracted BTP after spiking to olive flounder muscle, $0.025 \mathrm{pg}$. $\mathbf{d}$ Standard curve of BTP

Table 2 Validation summary for analytical procedure of butaphosphan (BTP) in olive flounder muscle

\begin{tabular}{|c|c|c|c|c|c|c|}
\hline \multirow[t]{2}{*}{ Matrix } & \multirow{2}{*}{$\begin{array}{l}\text { Quantification } \\
\text { limit (mg/kg) }\end{array}$} & \multirow{2}{*}{$\begin{array}{l}\text { Test } \\
\text { concentration } \\
(\mathrm{mg} / \mathrm{kg})\end{array}$} & \multicolumn{2}{|c|}{ Intra-day recovery (mean \pm SD) } & \multicolumn{2}{|c|}{ Inter-day recovery (mean \pm SD) } \\
\hline & & & Recovery (\%) & CV (\%) & Recovery (\%) & CV (\%) \\
\hline \multirow[t]{2}{*}{ Muscle } & 0.0025 & 0.0025 & $104.2 \pm 8.0$ & 7.6 & $105.5 \pm 8.5$ & 8.1 \\
\hline & & 0.005 & $96.82 \pm 3.0$ & 2.8 & $95.3 \pm 3.3$ & 3.5 \\
\hline
\end{tabular}



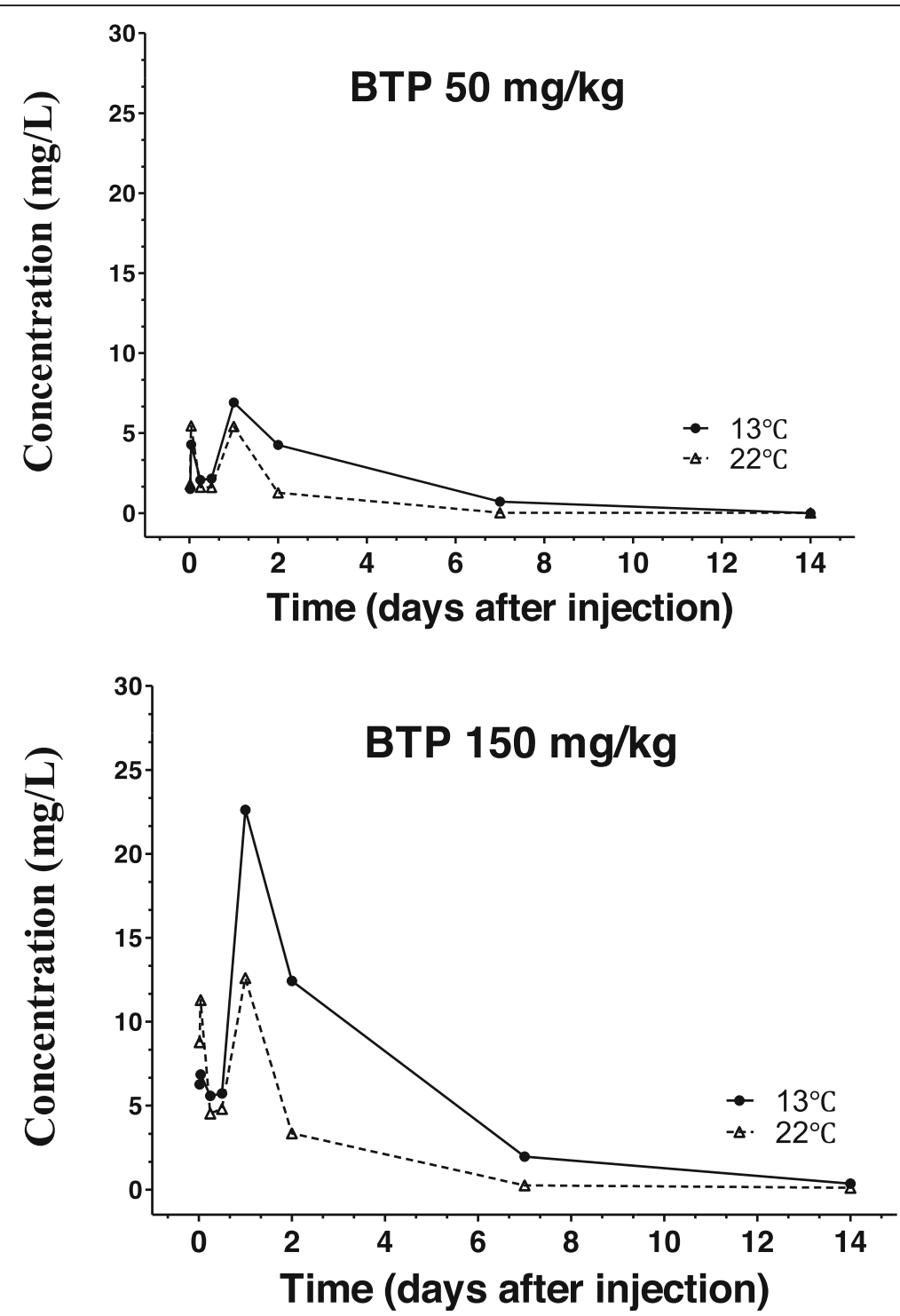

Fig. 3 Plasma concentration of BTP after intramuscular injection in olive flounder. Mean values were presented without error bars for clarity $(n=$ 5 for each time point). Levels at time 0 (non-detectable levels, $n=5$ ) were omitted to avoid complication, and the first symbols denote levels at $0.5 \mathrm{~h}$ after injection

Sun et al. 2016). In the current procedure and previous studies, recovery rates with the biological samples utilized were equally satisfactory, indicating that BTP recovery from animal tissues was not an obstacle in residue analysis.

We attempted to delineate the pharmacokinetic characteristics of BTP in the olive flounder by employing the analytical procedure established in the present study. One important purpose for characterizing the pharmacokinetic parameters of a drug is its relation to the temporal aspects of pharmacological activity. For example, the duration of activity can be approximately linked to the time a drug stays in the body. In turn, time is dependent on the elimination half-life $\left(t_{1 / 2 \mathrm{E}}\right)$ from plasma. The plasma $t_{1 / 2 \mathrm{E}}$ of BTP was extremely short, indicating that the duration of activity could also be quite brief if the drug works directly to exert its biological effects (Meyer and Fish, 2008). However, in the case of BTP, the duration of action is not likely to be closely linked to $t_{1 / 2 \mathrm{E}}$ as it attenuates stress symptoms acting indirectly, i.e., it stimulates adenosine-5'-triphosphate (ATP) production and the elevated ATP amount helps reduce detrimental stress responses (Hasi et al. 2004; Seo et al. 2019). By acting indirectly, the pharmacological actions can outlast tissue levels. In other words, even when BTP had already been eliminated due to incorporation into biomolecules as the phosphorus element (Rolling et al. 2010), biological actions can still occur.

An interesting phenomenon observed in the pharmacokinetic study was that the plasma BTP initially reached a 
Table 3 Pharmacokinetic parameters for plasma BTP level changes after intramuscular injection in olive flounder

\begin{tabular}{|c|c|c|c|c|c|}
\hline \multirow[t]{2}{*}{ Parameters } & \multirow[t]{2}{*}{ Units } & \multicolumn{2}{|c|}{$13^{\circ} \mathrm{C} \pm 3^{\circ} \mathrm{C}$} & \multicolumn{2}{|c|}{$22^{\circ} \mathrm{C} \pm 3^{\circ} \mathrm{C}$} \\
\hline & & $50 \mathrm{mg} / \mathrm{kg}$ & $150 \mathrm{mg} / \mathrm{kg}$ & $50 \mathrm{mg} / \mathrm{kg}$ & $150 \mathrm{mg} / \mathrm{kg}$ \\
\hline$C_{\max }$ & $\mathrm{mg} / \mathrm{L}$ & 6.910 & 22.623 & 5.445 & 5.445 \\
\hline$T_{\max }$ & days & 1.000 & 1.000 & 0.042 & 1.000 \\
\hline$t_{1 / 2 \mathrm{E}}$ & days & 1.877 & 2.220 & 1.363 & 1.977 \\
\hline$v_{\mathrm{d}}$ & L & 5.751 & 6.601 & 10.188 & 16.479 \\
\hline $\mathrm{Cl}$ & L/day & 2.124 & 2.061 & 5.180 & 5.779 \\
\hline$A U C_{0-\infty}$ & mg/L·day & 23.539 & 72.785 & 9.653 & 25.957 \\
\hline $\mathrm{MRT}_{0-\infty}$ & days & 2.674 & 2.927 & 1.382 & 1.970 \\
\hline $\mathrm{AUMC}_{0-\infty}$ & $\mathrm{mg} / \mathrm{L} \cdot \mathrm{day}^{2}$ & 62.954 & 213.075 & 13.339 & 51.147 \\
\hline
\end{tabular}

$C_{\text {max }}$ maximum concentration, $T_{\max }$ time reaching maximum concentration, $t_{1 / 2 E}$ half-life for elimination phase, $V_{d}$ volume of distribution, $\mathrm{Cl}$ clearance, $A U C_{O-\infty}$ area-under-the-time curve to infinity, $A U M C_{0-\infty}$ area-under-the-moment curve to infinity, $M R T_{0-\infty}$ mean residence time to infinity, $n=5$ for each parameter

high level after injection and then declined transiently. Subsequently, the level increased to reach higher peaks than the first one. The rationale underlying the occurrence of this peculiar pattern was unclear. One possible hypothesis explaining this biphasic pattern is the possibility of two discrete mobilization routes for BTP from the muscle to plasma via routes similar to multiple absorption sites model (Gabrielsson and Weiner 2000). Based on this model, some BTP molecules will immediately enter capillary vessels on arrival, and the remaining slower molecules will diffuse out to a wide tissue range, before entering into the vascular compartments. Muscle BTP concentrations did not differ between the two bath temperatures,

Table 4 Pharmacokinetic parameters for muscle BTP level changes after intramuscular injection in olive flounder

\begin{tabular}{|c|c|c|c|c|c|}
\hline \multirow[t]{2}{*}{ Parameters } & \multirow[t]{2}{*}{ Units } & \multicolumn{2}{|l|}{$13 \pm 3^{\circ} \mathrm{C}$} & \multicolumn{2}{|l|}{$22 \pm 3^{\circ} \mathrm{C}$} \\
\hline & & $50 \mathrm{mg} / \mathrm{kg}$ & $150 \mathrm{mg} / \mathrm{kg}$ & $50 \mathrm{mg} / \mathrm{kg}$ & $150 \mathrm{mg} / \mathrm{kg}$ \\
\hline$k_{12}$ & day $^{-1}$ & 2.103 & 2.406 & 2.178 & 1.474 \\
\hline$k_{21}$ & day $^{-1}$ & 0.322 & 0.462 & 0.196 & 0.553 \\
\hline$C_{\max }$ & $\mathrm{mg} / \mathrm{kg}$ & 1.662 & 4.428 & 1.456 & 3.219 \\
\hline$T_{\max }$ & days & 0.150 & 0.121 & 0.246 & 0.071 \\
\hline$t_{1 / 2 \mathrm{E}}$ & days & 7.131 & 8.372 & 8.296 & 7.002 \\
\hline$V_{\mathrm{d}}$ & $L$ & 13.5 & 23.743 & 13.477 & 40.826 \\
\hline$V_{\mathrm{d} 2}$ & $L$ & 149.466 & 123.763 & 149.466 & 108.798 \\
\hline $\mathrm{Cl}$ & L/day & 19.171 & 14.452 & 22.863 & 17.160 \\
\hline $\mathrm{AUC}_{0-\infty}$ & mg/kg·day & 2.608 & 10.379 & 2.187 & 8.741 \\
\hline AUCM & $\mathrm{mg} / \mathrm{kg} \cdot \mathrm{day}^{2}$ & 19.725 & 106.512 & 16.086 & 76.403 \\
\hline $\mathrm{MRT}_{0-\infty}$ & days & 7.563 & 10.262 & 7.356 & 8.740 \\
\hline
\end{tabular}

$k_{12}$ rate constant to central compartment, $k_{21}$ rate constant to peripheral compartment, $V d$ volume of distribution, $C_{\max }$ maximum concentration, $T_{\max }$ time reaching maximum concentration, $t_{1 / 2 E}$ half-life for elimination, $V_{d}$ central volume of distribution, $V_{d 2}$ peripheral volume of $\mathrm{Cl}$, clearance; $A U C_{0-\infty}$ areaunder-the-time curve, $A U M C$ area-under-the-moment curve, $M R T_{0-\infty}$ mean residence time from zero to infinity, $n=10$ for each parameter implying that distribution from the site of injection was not markedly influenced by body temperatures.

The patterns of overall BTP plasma concentrations demonstrated dual peak characteristics as briefly described above, with such a case interpreted as a drug with either multiple absorption sites (Gabrielsson and Eeiner 2000) or a drug that exhibits enterohepatic recirculation (Funaki 1999). In the case of such drugs, standard compartmental models, either single- or multiple-compartment, are not applicable. However, in the muscle residue levels, the overall pattern exhibited profiles similar to a two-compartment model. Hence, the non-compartmental analysis was applied to analyze both plasma and muscle levels. Noncompartmental analysis employed for the present BTP data was developed for easier application when there is uncertainty in true underlying compartments while compromising some accuracy of estimation (Zhang et al. 2010). Thus, although it is possible to figure out general tissue patterns of BTP residues, the present results can be considered as a further validation of developed analytical methods rather than definitive estimation of pharmacokinetic parameters.

Plasma pharmacokinetic parameters indicated that BTP quickly reached peak levels and disappeared. The rapid disappearance of BTP was characterized by short MRT (<11 days) since MRT is an estimate of how long a drug molecule stays in the body before complete elimination (Durisova 2014). Although only limited information is currently available, the pharmacokinetic behavior of BTP in the olive flounder appeared qualitatively similar to that in other animal species. In piglets, for example, BTP achieves peak levels as quickly as $18.6 \mathrm{~min}$, with a reasonably efficacious absorption rate of $74.7 \%$ (Sun et al. 2016), and rapid plasma. Furthermore, rapid clearance from the body was observed in horses, demonstrating a decline in plasma BTP from $87.8 \mu \mathrm{g} / \mathrm{ml}$ peaks to undetectable levels in $24 \mathrm{~h}$ (Du et al. 2004).

Furthermore, experiments were performed at two different water temperatures: $22^{\circ} \mathrm{C}$ as the optimal temperature, and $13{ }^{\circ} \mathrm{C}$ representing the low temperature at which the fish eats feed. Notably, higher water temperature conferred lower BTP peak concentrations and lower bioavailability compared with the lower temperature. This temperature dependence could be linked to a more efficient elimination when the fish is maintained at a higher temperature. In fishes, similar temperature dependency has been reported with the antimicrobial agent, oxolinic acid (Kleinow et al. 1994).

Another important objective of pharmacokinetic studies is consumer safety, particularly when the drug is administered to a food animal. Undoubtedly, olive founder is one of the most important aquaculture species in Korea, and BTP is currently employed with this fish (National Institute 

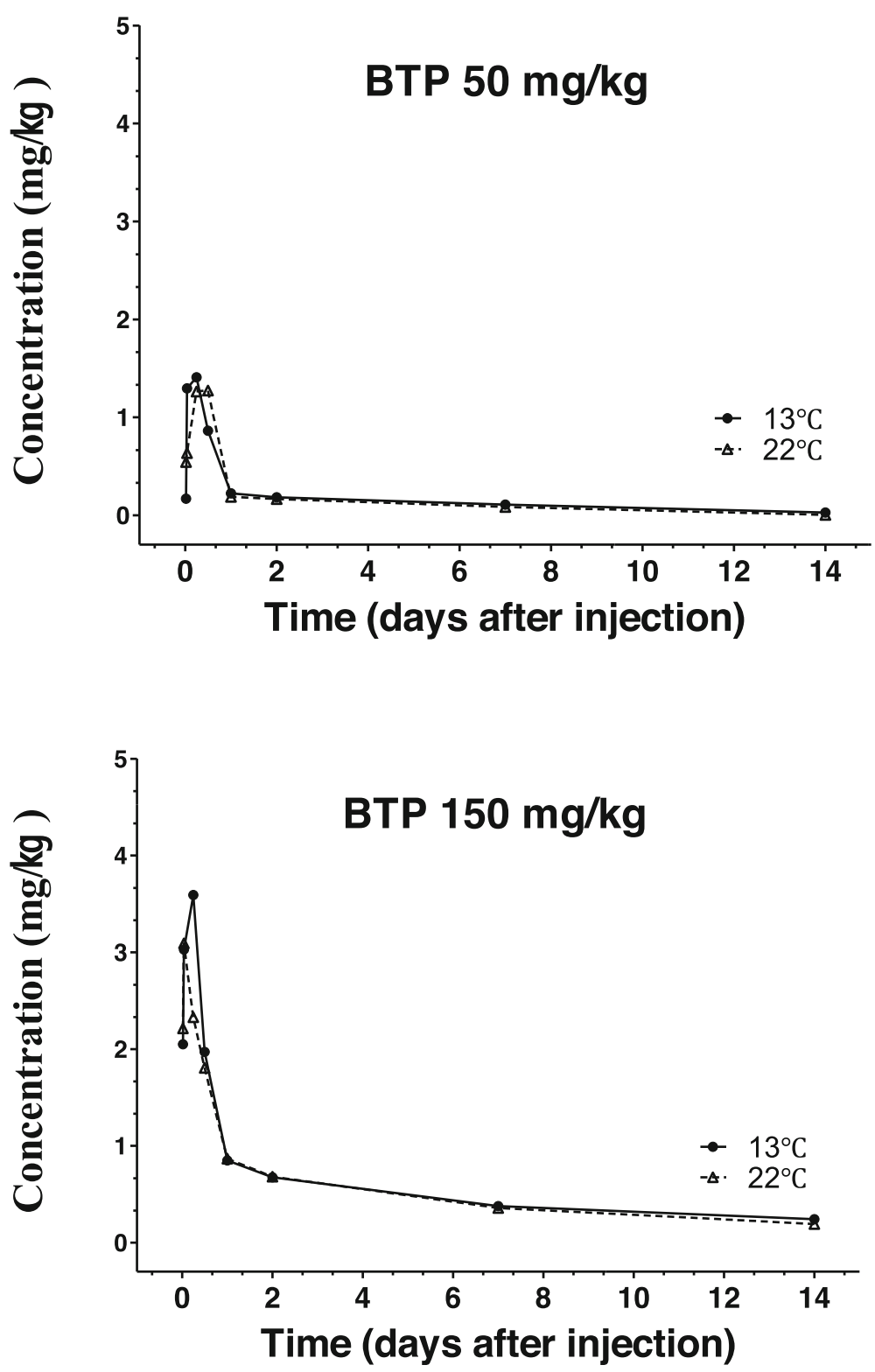

Fig. 4 Muscle concentration of BTP after intramuscular injection in olive flounder. Mean values were presented without error bars for clarity $(n=$ 10 for each time point). Levels at time 0 (non-detectable levels, $n=10$ ) were omitted to avoid complication, and the first symbols denote levels at $0.5 \mathrm{~h}$ after injection

of Fisheries Sciences 2018). According to the related regulations (Korea Ministry of Food and Drug Administration 2017), the maximally allowable drug residue levels need to be identified in edible tissues, the muscle in the case of fish. At harvest for human consumption, fish should not contain drugs exceeding the allowable concentrations (maximum residue limit, MRL). Withdrawal time, the time after which harvesting is possible after the final drug use, will then depends on residue levels. Due to these food safety reasons, determination of both MRL and withdrawal time are crucial for all animal drugs used in aquaculture. Residue levels of an aquaculture drug are monitored for the purpose of establishing consumer safety. According to the analysis by the European Agency for the Evaluation of Medicinal Products (European Medicines Agency 2013), daily intake of BTP $600 \mu \mathrm{g} / \mathrm{kg}$ is safe for lifetime use in humans. The estimation of a withdrawal period was not possible as peak tissue levels were too low compared with the MRL.

Following the use of BTP in farms, the residue levels in olive flounder muscles may concern consumers regarding its safety in humans. The safety estimation based on muscle concentrations and the theoretical tolerable level indicates that BTP is extremely safe and that such concern is not legitimate. 


\section{$13^{\circ} \mathrm{C}$}

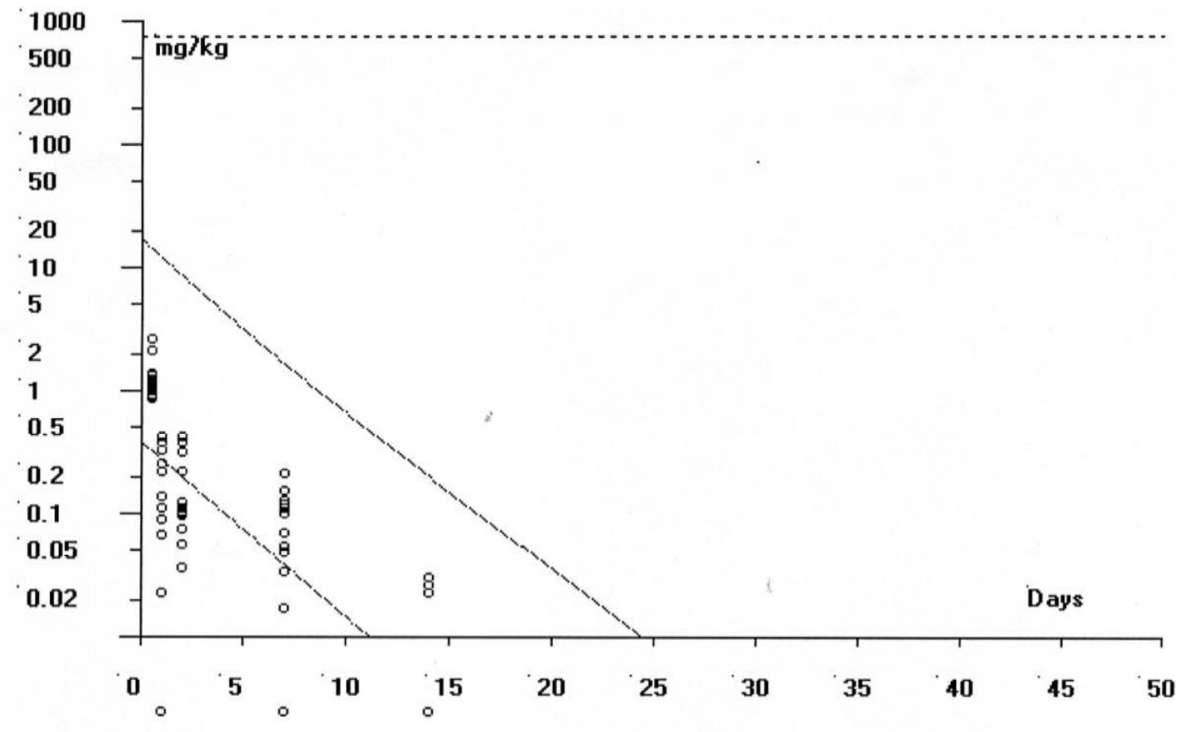

\section{$22^{\circ} \mathrm{C}$}

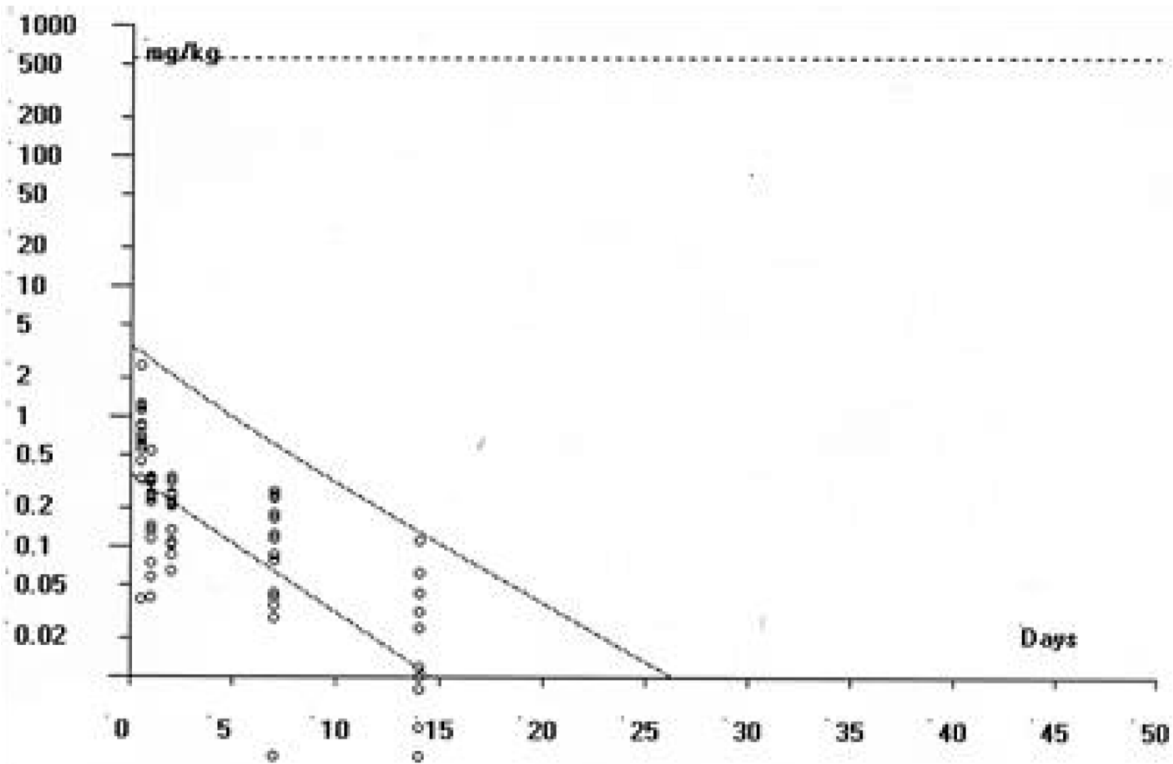

Fig. 5 Muscle concentration of BTP after intramuscular injection in olive flounder. Dots represent all muscle residue levels $(n=15$ fish for each time point), and the two broken lines indicate upper and lower confidence limits of the highest concentrations possible, respectively. The top horizontal lines represent maximally allowable residue levels for a fish $(571.4 \mathrm{mg} / \mathrm{kg}$ ) calculated from acceptable daily intake information (36 mg/person)

\section{Conclusion}

In conclusion, a sensitive quantification technique for BTP was established using LC-MS/MS analytical procedures.
Based on this method, established particularly for olive flounder plasma and muscles, it was possible to delineate the pharmacokinetic behavior of BTP in the fish. 


\section{Abbreviations}

BTP: Butaphosphan; DO: Dissolve oxygen; LC-MS/MS: Liq2uid chromatography coupled with tandem mass spectrometry; MRM: Multiple residue monitoring; MRL: Maximum residue limit

\section{Acknowledgements}

The work was supported by a Grant from the National Institute of Fisheries Science, Republic of Korea (Grant no. R2019058).

\section{Authors' contributions}

$J H L, J S B, C W L, C Y Y$, and JSC performed animal experiments and chemical analysis. SHC and YJK designed the study and guided chemical analysis procedures. KHP formulated the whole study. The author(s) read and approved the final manuscript.

\section{Funding}

The study was supported by the National Institute of Fisheries Science, Republic of Korea (Grant no. R2019058).

\section{Availability of data and materials}

Not applicable.

\section{Ethics approval and consent to participate}

Experimental protocols were approved by the Animal Care and Use Committee of the Kunsan National University, Korea (Approval number, AE 2016-04).

\section{Consent for publication}

Not applicable.

\section{Competing interests}

The authors declare that they have no competing interests.

\section{Author details}

${ }^{1}$ Aquatic Disease Control Division, National Institute of Fisheries Science, 216 Gijanghaean-Ro, Gijang-Gun, Gyeongnam 46083, Korea. ²Department of Aquatic Life Medicine, College of Ocean Science \& Technology, Kunsan National University, 558 Daehak-ro, Gunsan City, Jeonbuk 54150, Korea. ${ }^{3}$ Department of Aquatic Life and Medical Sciences, Sun Moon University, 221 Sunmoon-ro, Asan City, Chungnam 31460, Korea.

Received: 5 September 2019 Accepted: 2 March 2020

Published online: 07 April 2020

\section{References}

Alkobaby Al. Effects of maternal injection with organic phosphorus and vitamin $B_{12}$ on reproductive performance and newly hatched offspring of Nile tilapia (Oreochromis niloticus). Proceedings, The $8^{\text {th }}$ International Symposium on Tilapia in Aquaculture, October 12-14, 2008, Cairo, Egypt; cals.arizona.edu/ azaqua/ista/ISTA8/FinalPapers. Accessed 20 Jan 2010.

Benez LZ. Pharmacokinetic parameters: which are necessary to define a drug substance? Eur J Respir Dis Supp. 1984;134:45-61.

Deniz A, Spiecker-Hauser U, Rehagen M. Efficacy of a butafosfan and vitamin

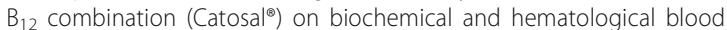
parameters in dogs treated with dexamethasone. Intern J Appl Res Vet Med. 2009;7:116-29.

Du XY. Studies on pharmacy and pharmacokinetics of compound butafosfan. Ph. D Thesis, China Agricultural University, 2004. www.dissertationtopic.net doc/1578105 (2004). Accessed 20 Jan 2020.

Durisova M. A physiological review and structure of mean residence times. Gen Physiol Biophys. 2014;33:75-80.

European Medicines Agency. Opinion of the committee for medicinal products for veterinary use on the establishment of maximum residue limits: name of the substance-butafosfan. EMEAN/MRL/003610/EXTN/0003 (2013). Accessed 20 Jan 2020.

Funaki T. Enterohepatic circulation model for population pharmacokinetic analysis. J Pharm Pharmacol. 1999:51:1143-8.

Fürll M, Deniz A, Westphal B, Illing C, Constable PD. Effect of multiple intravenous injections of butaphosphan and cyanocobalamin on the metabolism of periparturient dairy cows. J Dairy Sci. 2010;93:4155-64.
Fürll M, Wittek T, Gegenbach S, Schmidt B. Effects of preoperative application of butaphosphan and cyanocobalamin on reconvalescence, clinic-chemical parameters, and antioxidative metabolism and postoperative abomasal emptying in cows with abnormal dislocation. Tieraertl Prax. 2006;34:351-6.

Gabrielsson J, Weiner D. Pharmacokinetic and pharmacodynamic data analysis: concepts and applications, $3^{\text {rd }}$ eds. Sweden: Swedish Pharamceutical Press, Stockholm; 2000. p. 645-59.

Hasi S, Du X, Zhu B, Jiang J. Studies on effects of compound butaphosfan solution on endurance capability and energy metabolism in mice. Chin J Anim Vet Sci. 2004;35:290-4

Hasi S, Jiang J, Du X, Zhu B. Anti-cold stress effects and mechanisms of compound butaphosphan solution. Prog Vet Med. 2005a;26:59-62.

Hasi S, Jiang J, Zhu B, Du X. Studies on anti-heat stress effects and mechanisms of compound butaphosfan solution. Acta Vet Zootech Sin. 2005b;36:1334-8.

Hekman P. Withdrawal-time calculation program WT1.4. London, UK: European agency for the evaluation of medicinal products (EMEA); 1996.

Kleinow KM, Jarboe HH, Shomaker HE. Comparative pharmacokinetics and bioavailability of oxolinic acid in channel catfish (Ictalurus punctatus) and rainbow trout (Oncorrhynchus mykiss). Can J Fish Aquat Sci. 1994:51:1205-11.

Korea Ministry of Food and Drug Administration (2017) Principles of Standard Establishment for Foods. p. 155. https://mfds.go.kr/brd/m_218/list.do? Accessed 20 Jan 2020.

Korea Rural Economic Institute. 2017-Food Balance Sheet, 2017.

Mechesso AF, Kim Y, Park S. Effects of butaphosphan and cyanocovalamin combination on plasma immune and biochemical parameters of olive flounder (Paralichthys olivaceus) subjected to crowding stress. Aquacult Res. 2019;50:1611-7.

Meyer RE, Fish RE. Pharmacology of injectable anesthetics, sedatives, and tranquilizers. In: Anesthesia and analgesia in laboratory animals, $2^{\text {nd }}$ eds. San Diego: Academic Press; 2008. 27-82.

National Institute of Fisheries Sciences. Aquatic medicine catalogue. http://www. nifs.go.kr/adms/index.ad (2018) Accessed 20 Jan 2010.

Pereira RA, Fensterseifer S, Barcelos VB, Martins CF, Schneider A, Schmitt E, Pfeifer LFM, Del Pino FAB, Corrêa MN. (2013b) Metabolic parameters and dry matter intake of ewes treated with butaphosphan and cyanocobalamin in the early postpartum period. Small Rum Res. 2013b;114:140-5.

Pereira RA, Montagner P, Schneider A, Schmitt E, Rabassa VR, Pfeifer LFM, Del Pino FAB, Pulga ME, Corrêa MN. Effect of butaphosphan and cyanocobalamin on postpartum metabolism and milk production in dairy cows. Animal. 2013a;7:1143-7.

Rolling E, Berghaus RD, Rapnicki P, Godden SM, Overton MW. The effect of injectable butaphosphan and cyanocobalamin on postpartum serum betahydroxybutyrate, calcium, and phosphorus concentrations in dairy cattle. J Dairy Sci. 2010;93:978-87.

Seo JS, Lee JH, Park JJ, Choi JS, Bae JS, Lee CW, Yang CY, Kang YJ, Choi SH, Park $\mathrm{KH}$. Biochemical and stress-attenuating effects of butaphosphancycnocobalamin combination drug in olive flounder Paralichthys olivaceus. Fish Sci. 2019 (published online December 16). https://doi.org/10.1007/ s12562-019-01389-x.

Sun F, Wang J, Yang S, Zhang S, Shen J, Xingyuan C. Pharmacokinetics of butafosfan after intravenous and intramuscular administration in piglets. J Vet Pharmacol Ther. 2016;40:203-5.

Tabeleão VC, Schwegler E, Pereira RA, Krause ART, Montagner P, Feijó JO, Schneider A, Schmitt E, Brauner CC, Rabassa VR, Del Pino FAB, Corrêa MN. Combined butaphosphan and cyanocobalamin on the glucose metabolism of dairy cows after calving. Arq Bras Med Vet Zootec. 2017;69:317-24.

Van de Vis H, Kruijt-Kloosterboer K, Veldman M. Test for potential protective effects of Catosal ${ }^{\oplus}$ on mortality of fish due to temporary hypoxia. Internal Report No. C061/04, RIVO-Netherlands Institute for Fisheries Research, Ymuiden, Netherlands. edepot.wur.nl/148440 (2004). Accessed 20 Jan 2020.

Van der Staay DE, Groot J, Van Reenen CC, Hoving-Bolink AH, Schuurman T, Schmidt BH. Effects of butaphosphan on salivary cortisol and behavioral response to social stress in piglets. J Vet Pharmacol Ther. 2007;30:410-6.

Zhang Y, Hou M, Zhou J, Xie S. PKSolver: an add-in program for pharmacokinetic and pharmacodynamics data analysis in Microsoft Excel. Computer Methods Programs Biomed. 2010;99:306-14.

\section{Publisher's Note}

Springer Nature remains neutral with regard to jurisdictional claims in published maps and institutional affiliations. 